\title{
Efeito do nível nutricional antes e após a ovulação sobre a taxa de gestação e a prolificidade em ovelhas Santa Inês
}

\author{
[Effect of the nutritional level before and after ovulation on pregnancy rate and \\ prolificacy in Santa Ines ewes] \\ G.A. Saunders ${ }^{1}$, N.G. Alves ${ }^{1}$, J.R.O. Pérez ${ }^{1}$, J.C. Souza ${ }^{1}$, A.M. Moura ${ }^{2,}$ J.A. Muniz ${ }^{1}$, \\ R.R. Lima ${ }^{1}$, G.B. Lazarin ${ }^{1}$ \\ ${ }^{1}$ Universidade Federal de Lavras - Lavras, MG \\ ${ }^{2}$ Aluno de pós-graduação - Universidade Federal de Lavras - Lavras, MG
}

\begin{abstract}
RESUMO
Quarenta e três ovelhas foram distribuídas em quatro tratamentos em um delineamento de blocos casualizados. Os tratamentos consistiram no fornecimento de dietas de flushing, formuladas com farelo de soja (FFS) ou com glúten de milho e farelo de algodão (FGM+FA) por 28 dias antes da ovulação, seguido pelo fornecimento de dietas de flushing ou de uma dieta de mantença (DM) durante 28 dias após a ovulação: T1 - FFS antes e após a ovulação (n=12); T2 - FFS antes da ovulação e DM após (n=11); T3 FGM+FA antes e após a ovulação $(n=10)$; T4 - FGM+FA antes da ovulação e DM após $(n=10)$. O ganho de peso e o peso final não diferiram $(\mathrm{P}>0,05)$ entre os animais dos tratamentos. $\mathrm{O}$ ECC final foi maior $(\mathrm{P}<0,05)$ nas ovelhas do tratamento T3 do que nas do tratamento T2. A concentração de $\mathrm{N}$-ureico foi maior $(\mathrm{P}<0,05)$ nas ovelhas dos tratamentos T1 e T3 do que naquelas dos tratamentos T2 e T4. A taxa de gestação e a prolificidade não diferiram $(\mathrm{P}>0,05)$ entre os animais. As dietas de flushing antes da ovulação, seguidas pelo fornecimento destas mesmas dietas ou de uma dieta de mantença após a ovulação, não alteraram a taxa de gestação e a prolificidade.
\end{abstract}

Palavras-chave: farelo de soja, glúten de milho, proteína degradável no rúmen, concentração plasmática de N-ureico

\begin{abstract}
Forty-tree ewes were assigned to four treatments in a randomized block design. The treatments consisted of two flushing diets, composed of soybean meal (SMF) or corn gluten and cottonseed meal (CG+CMF) furnished for 28 days before ovulation, and feeding with flushing diets or a maintenance diet (MD) for 28 days after ovulation: $T 1-(S M F)$ before and after ovulation $(n=12) ; T 2-S M F$ before ovulation and a $M D$ after $(n=11) ; T 3-C G+C M F$ before and after ovulation $(n=10) ; T 4-C G+C M F$ before ovulation and $M D$ after $(n=10)$. The gain in $B W$ and the final $B W$ did not differ $(P>0,05)$ between treatments. The final $B C$ was higher $(P>0,05)$ in ewes in T3 treatment than in those in treatment $T 2$. The urea $N$ concentration was higher $(P<0,05)$ in ewes in treatments $T 1$ and T3 than those in treatments $T 2$ and T4. The pregnancy rate and prolificacy did not differ $(P>0,05)$ between treatments. The flushing diets before ovulation and feeding with this same diet or a maintenance diet after ovulation did not alter the pregnancy rate and prolificacy.
\end{abstract}

Keywords: Soybean meal, corn gluten, degradable rumen protein, plasma urea $N$ concentration

\section{INTRODUÇÃO}

Técnicas nutricionais, como o flushing, são estratégias utilizadas para aumentar a fertilidade.

Recebido em 1 de abril de 2011

Aceito em 22 de maio de 2012

E-mail:nadja@dzo.ufla.br
O flushing refere-se ao aumento do aporte nutricional, principalmente com alimentos energéticos, antes da cobertura visando ao aumento da taxa de ovulação. Os efeitos do flushing com dietas ricas em proteína ainda são 
escassos e contraditórios na literatura. Enquanto alguns autores (Molle et al., 1997; Ocak et al., 2006) demonstraram que o flushing com concentrados proteicos aumentou a taxa de ovulação e a prolificidade, outros observaram que essa suplementação também ocasionou maior mortalidade embrionária (Molle et al., 1995) e elevação da concentração de nitrogênio ureico no leite, o que foi inversamente relacionado à taxa de concepção (Branca et al., 2000).

O flushing difere quanto ao momento em que o tratamento é iniciado e quanto à sua duração. $\mathrm{O}$ nível (Parr et al., 1987; Rhind et al., 1989; Abecia et al., 1997) ou o momento (Molle et al., 1997) da suplementação com energia ou proteína, bem como a fonte de proteína utilizada (Landau et al., 1996), podem ter consequências críticas para a eficiência reprodutiva de ovelhas porque a exigência de nutrientes para o ótimo crescimento folicular pode ser diferente daquela para o desenvolvimento do embrião (O' Callaghan e Boland, 1999).

Este experimento teve como objetivos avaliar a concentração plasmática de $\mathrm{N}$-ureico, a taxa de gestação e a prolificidade de ovelhas submetidas ao flushing com dietas contendo fontes de proteína de diferentes degradabilidades ruminais e que receberam dietas de flushing ou uma dieta de mantença após a ovulação.

\section{MATERIAL E MÉTODOS}

O experimento foi realizado no Setor de Ovinocultura do Departamento de Zootecnia da Universidade Federal de Lavras (UFLA), no período de setembro a dezembro de 2007. Foram utilizadas 43 ovelhas da raça Santa Inês, multíparas, não gestantes, em bom estado sanitário e clínico geral, com peso médio de $51,33 \pm 0,15 \mathrm{~kg}$ e escore de condição corporal (ECC) entre 2,25 e 3,25. A avaliação do ECC foi feita considerando-se uma escala de 0 a 5 , sendo 0 = emaciada e $5=$ muito gorda, segundo Gordon (1997). As ovelhas foram distribuídas em um delineamento de blocos, sendo estes formados por três faixas de ECC $(2,25$ a 2,50; 2,75 e 3,00 a 3,25). Dentro de cada bloco, as ovelhas foram distribuídas aleatoriamente aos tratamentos.

As ovelhas receberam dietas de flushing por 28 dias antes da data prevista para a ovulação. Após a ovulação e a cobertura, metade das ovelhas de cada tratamento recebeu dieta de flushing e metade recebeu uma dieta de mantença, durante 28 dias, resultando em quatro tratamentos: T1 flushing com farelo de soja (FFS) antes e após a ovulação $(n=12)$; T2 - FFS antes da ovulação e dieta de mantença após a ovulação $(\mathrm{n}=11)$; T3 flushing com glúten de milho e farelo de algodão (FGM+FA) antes e após a ovulação $(n=10)$ e T4 - FGM+FA antes da ovulação e dieta de mantença após a ovulação $(\mathrm{n}=10)$.

As dietas foram calculadas conforme o AFRC (Agricultural...,1993), considerando-se o peso vivo médio das ovelhas de $55 \mathrm{~kg}$ e o consumo diário de $1,5 \mathrm{~kg}$ e $1,0 \mathrm{~kg}$ de MS para as dietas de flushing e de mantença, respectivamente. A composição das dietas experimentais em ingredientes e nutrientes é apresentada na Tab. 1.

As ovelhas foram mantidas em baias coletivas de $10 \mathrm{~m}^{2}$, construídas de alvenaria, cobertas com telhas de barro e com casca de café como cama. As dietas foram fornecidas na forma de mistura completa, duas vezes ao dia. O consumo das dietas de flushing foi ajustado em função da porcentagem de peso vivo, para que o consumo de MS fosse semelhante entre as ovelhas que receberam estas dietas. A dieta de mantença foi fornecida em quantidade fixa para alcançar o consumo de $1 \mathrm{kgMS} /$ animal/dia. As sobras de cada baia foram retiradas e pesadas, para determinação do consumo do grupo e estimativa do consumo médio individual (CMI). Amostras dos alimentos e das sobras diárias foram coletadas e armazenadas a $-20^{\circ} \mathrm{C}$. Análises bromatológicas de amostras compostas por semana foram realizadas no Laboratório de Ciência Animal do Departamento de Zootecnia da UFLA. As análises de MS, PB, EE, fibra em detergente neutro corrigido para cinzas (FDNc) e cinzas foram realizadas de acordo com Silva e Queiroz (2002).

As ovelhas foram pesadas e o ECC foi avaliado semanalmente, até o fim do experimento. 
Efeito do nível nutricional...

Tabela 1 Composição percentual e química de dietas consumidas por ovelhas durante o período experimental

\begin{tabular}{lccccc} 
& \multicolumn{5}{c}{ Dietas } \\
\cline { 2 - 5 } \multicolumn{1}{c}{ Ingredientes } & \multicolumn{2}{c}{ Antes da ovulação } & \multicolumn{3}{c}{ Após a ovulação } \\
& FFS & FGM+FA & FFS & FGM+FA & Mantença \\
\hline Silagem de milho (\%MS) & 72,14 & 73,27 & 70,05 & 69,57 & 75,95 \\
Farelo de soja (\%MS) & 13,98 & - & 15,04 & - & 8,66 \\
Glúten de milho (\%MS) & - & 7,45 & - & 8,48 & - \\
Farelo de algodão (\%MS) & - & 4,96 & - & 5,65 & - \\
Polpa (\%MS) & 9,25 & 9,55 & 9,95 & 10,87 & 12,84 \\
Sal mineral (\%MS) & 4,62 & 4,77 & 4,97 & 5,43 & 2,55 \\
Nutrientes & & & & & 36,39 \\
MS (\%MN) & 41,31 & 41,22 & 38,49 & 36,29 & 92,75 \\
MO (\%MS) & 90,89 & 91,21 & 90,23 & 89,73 & 10,22 \\
PB (\%MS) & 12,04 & 12,25 & 12,68 & 13,84 & 67,00 \\
PDR (\%PB) & 79,30 & 65,60 & 67,10 & 52,80 & 33,00 \\
PNDR (\%PB) & 20,70 & 34,40 & 32,90 & 47,20 & 46,65 \\
FDN (\%MS) & 43,81 & 40,83 & 42,22 & 41,77 & 3,57 \\
EE (\%MS) & 3,11 & 2,90 & 3,48 & 3,43 & 32,32 \\
CNF (\%MS) & 31,93 & 35,23 & 31,85 & 30,69 & 7,25 \\
Cinzas (\%MS) & 9,11 & 8,79 & 9,77 & 10,27 & 2,78 \\
EM (Mcal/dia) & 3,96 & 3,93 & 3,81 & 3,42 & \\
\hline
\end{tabular}

FFS: dieta de flushing com farelo de soja; FGM+FA: dieta de flushing com glúten de milho e farelo de algodão; MS: matéria seca; PB: proteína bruta; PDR: proteína degradável no rúmen estimada pelo CNCPS (Cornell University, 2003); PNDR: proteína não degradável no rúmen estimada pelo CNCPS; FDN: fibra em detergente neutro; EE: extrato etéreo; CNF: carboidrato não fibroso determinado pela equação: $\mathrm{CNF}=100$ - (PB + EE + FDNc + cinzas); EM: energia metabolizável estimada pelo SRNS (Smal..., 2008). ${ }^{1}$ Níveis de garantia por kg do produto: $80 \mathrm{~g}$ de P, $18 \mathrm{~g}$ de $\mathrm{Mg}, 150 \mathrm{~g}$ de $\mathrm{Na}, 15 \mathrm{~g}$ de S, $125 \mathrm{mg}$ de $\mathrm{Ca}, 65 \mathrm{mg}$ de Co, $95 \mathrm{mg}$ de I, $1500 \mathrm{mg}$ de $\mathrm{Mn}, 30 \mathrm{mg}$ de Se, 350mg de Zn, $800 \mathrm{mg}$ de F, $30.000 \mathrm{UI}$ de vit. A, 3.000 UI de vit. D, 60 UI de vit. E.

Amostras de sangue das ovelhas foram coletadas por punção da veia jugular nos dias sete, 14, $21 \mathrm{e}$ 28 após a ovulação, em tubos de vidro de coleta a vácuo com anticoagulante EDTA, para dosagem de ureia no plasma. As amostras foram coletadas quatro horas após a alimentação, acondicionadas em caixa de isopor com gelo e centrifugadas a 1582 x g para a obtenção de plasma. As análises de ureia foram realizadas por método colorimétrico enzimático, utilizando-se kit comercial (Ureia 500®, Doles Reagentes e Equipamentos para Laboratórios Ltda., Belo Horizonte, MG). Posteriormente, os dados de ureia no plasma foram transformados para $\mathrm{N}$ ureico, multiplicando-se o valor de ureia encontrado na análise por 0,4666 , equivalente à porcentagem do nitrogênio presente na molécula de ureia.

O protocolo de sincronização de estros foi iniciado no $17^{\circ}$ dia após o início do fornecimento das dietas de flushing, com a utilização de uma esponja intravaginal impregnada com $60 \mathrm{mg}$ de acetato de medroxiprogesterona (MAP60®, Tecnopec, Brasil) por 11 dias e aplicação de 300 UI de eCG (Novormon®, Syntex S.A.) e 50 $\mu \mathrm{g}$ de cloprostenol (Prolise®, ARSA S.R.L.), via intramuscular, no nono dia após a inserção da esponja intravaginal. A partir de 12 horas após a retirada da esponja, a manifestação de estros foi monitorada das oito às nove horas e das 17 às 18 horas, com auxílio de rufiões. As ovelhas que apresentaram estro foram cobertas por carneiros de fertilidade comprovada por exame andrológico.

O diagnóstico de gestação foi determinado por ultrassonografia transretal utilizando-se um aparelho marca CHISSON 500, com um transdutor linear de $5 \mathrm{MHz}$, o qual foi acoplado a uma extensão rígida $(3 \mathrm{~cm}$ de diâmetro e $16 \mathrm{~cm}$ de comprimento) que permitiu sua manipulação no 
reto. Os exames foram realizados no dia 28 e confirmados entre os dias 35 e 42 após a cobertura. Em ambos os exames foram visualizados os envoltórios fetais e o feto, e foi realizada a avaliação da viabilidade fetal (movimentos e batimentos cardíacos), bem como a contagem do número de fetos (Oliveira et al., 2004). A taxa de gestação no dia 35 (número de ovelhas diagnosticadas gestantes/total de ovelhas sincronizadas x 100) e a prolificidade (número de cordeiros nascidos por ovelha parida) foram determinadas.

O ganho de peso e de ECC, o peso e o ECC final e a prolificidade foram submetidos à análise de variância, com comparação das médias pelo teste Tukey, adotando-se o nível de $5 \%$ de probabilidade (Statistical..., 1997). O modelo estatístico utilizado foi:

Yijk $=\mu+\mathrm{Ti}+\mathrm{Bj}+\varepsilon i j \mathrm{k}$, sendo:

$\mu$ uma constante inerente a cada observação;

Ti o efeito do tratamento $(i=1,2,3$ e 4$)$;

Bj o efeito da faixa de escore $(j=1,2$ e 3$)$;

عijk o erro experimental aleatório, independente, com distribuição normal de média zero e variância $\sigma 2(\mathrm{k}=1,2,3$ e 4$)$.

A concentração de $\mathrm{N}$-ureico foi analisada segundo um esquema em parcelas subdivididas no tempo, considerando os quatro tratamentos e os dias de coleta de sangue, com comparação de médias pelo teste Tukey, adotando-se o nível de $5 \%$ de probabilidade (Statistical..., 1997):

Yijk $=\mu+T_{i}+\varepsilon_{i j}+D_{k}+T_{i k}+\varepsilon_{i j k}$, sendo:

$\mu$ a média geral;

$\mathrm{T}_{\mathrm{i}} \mathrm{o}$ efeito do tratamento $(\mathrm{i}=1,2,3$ e 4$)$;

$\varepsilon_{\mathrm{ij}} \mathrm{o}$ erro experimental associado à parcela, considerado independente e identicamente distribuído de uma normal de média zero e variância $\sigma^{2}$;

$\mathrm{D}_{\mathrm{k}} \mathrm{o}$ efeito do tempo $(\mathrm{k}=1,2,3$ e 4$)$;

$\mathrm{TD}_{\mathrm{ik}}$ a interação entre o tratamento e o tempo;

$\varepsilon_{\mathrm{ijk}} \mathrm{o}$ erro experimental associado à subparcela, considerado independente e identicamente distribuído de uma normal de média zero e variância $\sigma^{2}$.

A variável qualitativa (taxa de gestação) foi comparada em tabela de contingência, aplicando- se $\mathrm{o}$ teste de qui-quadrado, a $5 \%$ de probabilidade (Statistical..., 1997).

\section{RESULTADOS E DISCUSSÃO}

As estimativas do consumo médio individual de MS e de nutrientes são apresentadas na Tab. 2. As dietas de flushing foram formuladas para fornecer as mesmas quantidades de nutrientes a fim de que a diferença entre as duas dietas estivesse principalmente na forma de degradação da proteína. Antes da ovulação, a estimativa do consumo médio individual de matéria seca e dos nutrientes foi semelhante entre as ovelhas que receberam a dieta de FFS (T1 e T2) e as que receberam a dieta de FGM+FA (T3 e T4). Após a ovulação, a estimativa de consumo médio individual de matéria seca foi semelhante às ovelhas que receberam as dietas de FFS (T1) e FGM+FA (T3), assim como foi semelhante às ovelhas que receberam a dieta de mantença (T2 e T4). A porcentagem de PB na dieta de FGM+FA fornecida após a ovulação foi $1,16 \%$ maior que a na dieta de FFS (Tab. 1), contudo a estimativa do consumo médio individual de PB pelas ovelhas que receberam as dietas de flushing (T1 e T3) após a ovulação foi semelhante, assim como a estimativa do consumo médio individual de $\mathrm{MO}$, CNF, EE, FDNc e cinzas também foi semelhante entre estes tratamentos. Após a ovulação, as ovelhas que receberam a dieta de mantença (T2 e T4) consumiram 58\% e 59\% do total de PB consumido pelas ovelhas que receberam as dietas de flushing (T1 e T3). As ovelhas dos tratamentos T1 e T3 consumiram 1,86 e 1,88 vez a exigência de $\mathrm{PB}$ de mantença. Em relação à EM, as ovelhas dos tratamentos T1 e T3 consumiram 1,56 e 1,40 vez a exigência de EM, em relação à exigência de mantença.

O ganho de peso e o peso final não diferiram $(\mathrm{P}>0,05)$ entre os animais dos tratamentos (Tab. 3). Os resultados deste estudo são similares aos de Molle et al. (1995), que, estudando ovelhas não suplementadas ou suplementadas com $270 \mathrm{~g}$ de farelo de soja ou $250 \mathrm{~g}$ de milho por 15 dias antes da cobertura até três semanas após a introdução do macho, não observaram diferença na alteração do peso corporal. 
Efeito do nível nutricional...

Tabela 2. Estimativa do consumo médio individual de matéria seca e de nutrientes por ovelhas antes da ovulação e durante 28 dias após a mesma

\begin{tabular}{cccccccccc}
\hline Tratamentos & \multicolumn{1}{c}{ Consumo de MS } & \multicolumn{7}{c}{ Nutrientes } & (kg/dia) \\
Antes da ovulação & $\cdots$ & $\mathrm{kg} /$ dia & \% do PV & MO & PB & CNF & EE & FDNc & Cinzas \\
\hline T1 & 1,692 & 3,00 & 1,539 & 0,202 & 0,548 & 0,051 & 0,737 & 0,153 \\
T2 & 1,586 & 2,90 & 1,441 & 0,192 & 0,502 & 0,050 & 0,696 & 0,145 \\
T3 & 1,628 & 3,00 & 1,483 & 0,200 & 0,580 & 0,047 & 0,657 & 0,144 \\
T4 & 1,600 & 2,90 & 1,460 & 0,196 & 0,562 & 0,047 & 0,656 & 0,140 \\
\hline Após a ovulação & & & & & & & \\
\hline T1 & 1,556 & 2,96 & 1,404 & 0,198 & 0,495 & 0,054 & 0,657 & 0,152 \\
T2 & 1,157 & 2,09 & 1,078 & 0,115 & 0,377 & 0,041 & 0,545 & 0,079 \\
T3 & 1,455 & 2,99 & 1,306 & 0,201 & 0,447 & 0,050 & 0,608 & 0,149 \\
T4 & 1,135 & 2,19 & 1,048 & 0,119 & 0,363 & 0,040 & 0,526 & 0,087 \\
\hline
\end{tabular}

MS: matéria seca; PV: peso vivo; MO: matéria orgânica; PB: proteína bruta; CNF: carboidratos não fibrosos; EE: extrato etéreo; FDNc: fibra em detergente neutro corrigido para cinzas.

Tabela 3. Média e erro-padrão do ganho de peso, do peso final, do ganho de escore de condição corporal e do escore corporal final de ovelhas durante o experimento, submetidas a diferentes dietas

\begin{tabular}{ccccc}
\hline Tratamentos & Ganho de peso & Peso final $^{1}$ & Ganho de ECC $^{2}$ & ECC final $^{2}$ \\
\hline T1 & $5,16 \pm 1,09$ & $56,82 \pm 2,04$ & $0,23 \pm 0,08 \mathrm{a}$ & $2,96 \pm 0,08 \mathrm{ab}$ \\
T2 & $5,12 \pm 1,14$ & $55,91 \pm 2,13$ & $-0,08 \pm 0,08 \mathrm{~b}$ & $2,67 \pm 0,08 \mathrm{~b}$ \\
T3 & $6,91 \pm 1,21$ & $58,15 \pm 2,25$ & $0,44 \pm 0,08 \mathrm{a}$ & $3,18 \pm 0,08 \mathrm{a}$ \\
T4 & $4,37 \pm 1,20$ & $53,97 \pm 2,24$ & $0,12 \pm 0,08 \mathrm{ab}$ & $2,86 \pm 0,08 \mathrm{ab}$ \\
\hline
\end{tabular}

Médias seguidas por letras minúsculas diferentes na mesma coluna diferem entre si, pelo teste Tukey $(\mathrm{P}<0,05) .{ }^{1}$ Ganho de peso e peso final em kg. ECC: escore de condição corporal. ${ }^{2}$ Ganho de ECC e ECC final expressos em unidades, em escala de 0 a 5 , sendo $0=$ emaciada e $5=$ obesa (Gordon, 1997).

O ganho de ECC foi maior $(\mathrm{P}<0,001)$ nas ovelhas que receberam os tratamentos $\mathrm{T} 1$ e $\mathrm{T} 3$, comparadas àquelas que receberam o tratamento T2. No entanto, o ganho de ECC das ovelhas do tratamento T4 não diferiu do observado naquelas dos tratamentos T1, T2 e T3 (Tab. 3). As ovelhas do tratamento $\mathrm{T} 3$ apresentaram maior ECC final $(\mathrm{P}<0,05)$ do que aquelas do tratamento T2. O ECC final das ovelhas dos tratamentos $\mathrm{T} 1$, T2 e T4 não diferiu $(\mathrm{P}>0,05)$, assim como não foi diferente $(\mathrm{P}>0,05)$ o ECC final das ovelhas dos tratamentos T1, T3 e T4 (Tab. 3). Não há uma explicação para as diferenças no ganho de ECC e no ECC final observado neste estudo, já que o ganho de peso não diferiu.

Costa (2001), avaliando o desempenho de bovinos confinados alimentados com dietas contendo fontes de proteína de diferentes degradabilidades, não observou diferença no ganho de peso entre os animais que consumiram dietas formuladas para exceder a quantidade de PDR, exceder a quantidade de PNDR ou atender as exigências de PDR e PNDR. O autor relatou que os animais que consumiram a dieta com a maior quantidade de PNDR apresentaram a condição corporal diferente dos demais, sugerindo a possibilidade de ter havido diferença na composição de ganho de peso. Apesar de o ganho de ECC ter sido menor $(\mathrm{P}<0,05)$ nas ovelhas que receberam $\mathrm{O}$ tratamento $\mathrm{T} 2$, em relação às que receberam os tratamentos T1 e T3, a taxa de gestação não foi reduzida $(\mathrm{P}>0,05)$ naquelas ovelhas. Considerando-se que o ECC das ovelhas durante os 28 dias após a ovulação permaneceu acima de 2,5, a influência do ECC sobre a taxa de gestação pode ter sido reduzida.

A concentração de $\mathrm{N}$-ureico diferiu entre os dias de coleta $(\mathrm{P}<0,01)$ e entre os tratamentos $(\mathrm{P}<0,001)$, mas não houve interação $(\mathrm{P}>0,05)$ entre os tratamentos e os dias (Tab. 4). A concentração de N-ureico no dia 21 foi maior $(\mathrm{P}<0,01)$ do que a no dia 28. A concentração de $\mathrm{N}$-ureico nestes dias não foi diferente $(\mathrm{P}>0,05)$ da observada nos dias sete e 14 . A concentração de $\mathrm{N}$-ureico foi maior $(\mathrm{P}<0,001)$ nas ovelhas que receberam as dietas de flushing (T1 e T3) do que naquelas que receberam a dieta de mantença (T2 e T4) após a ovulação. No entanto, não houve diferença $(\mathrm{P}>0,05)$ na concentração deste metabólito entre as ovelhas que receberam as dietas de flushing formuladas com as fontes de proteína de diferentes degradabilidades, assim como entre aquelas que receberam a dieta de mantença. 
Tabela 4. Média do N-ureico (mg/dL) de ovelhas experimentais nos dias sete, 14, 21 e 28 após a ovulação, submetidas a diferentes dietas

\begin{tabular}{cccccc}
\hline Dia & & & Tratamentos & & \\
& T1 & T2 & T3 & T4 & \\
7 & $17,00 \pm 1,17$ & $14,60 \pm 1,23$ & $21,20 \pm 1,30$ & $15,31 \pm 1,29$ & $17,03 \pm 0,63 \mathrm{AB}$ \\
14 & $19,27 \pm 1,17$ & $14,52 \pm 1,23$ & $21,40 \pm 1,30$ & $13,04 \pm 1,29$ & $17,06 \pm 0,63 \mathrm{AB}$ \\
21 & $23,15 \pm 1,17$ & $14,05 \pm 1,23$ & $21,27 \pm 1,30$ & $17,69 \pm 1,29$ & $19,04 \pm 0,63 \mathrm{~A}$ \\
28 & $17,79 \pm 1,17$ & $10,85 \pm 1,23$ & $20,68 \pm 1,30$ & $14,40 \pm 1,29$ & $15,93 \pm 0,63 \mathrm{~B}$ \\
Média & $19,30 \pm 0,66 \mathrm{a}$ & $13,51 \pm 0,69 \mathrm{~b}$ & $21,14 \pm 0,76 \mathrm{a}$ & $15,11 \pm 0,73 \mathrm{~b}$ & \\
\hline
\end{tabular}

Médias seguidas por letras minúsculas diferentes na mesma linha diferem entre si, pelo teste Tukey $(\mathrm{P}<0,001)$. Médias seguidas por letras maiúsculas diferentes na mesma coluna diferem entre si, pelo teste Tukey $(\mathrm{P}<0,01)$.

A substituição de farelo de soja por glúten de milho e farelo de algodão não foi efetiva em reduzir a concentração de $\mathrm{N}$-ureico a partir do $21^{\circ}$ dia do experimento, ocasionando, inclusive, aumento $(\mathrm{P}<0,05)$ desta concentração no $28^{\circ}$ dia. A explicação para estas observações não é clara, mas poderia estar relacionada ao menor valor biológico do perfil de aminoácidos absorvidos e ao maior catabolismo endógeno de aminoácidos em animais que recebem dietas contendo glúten de milho (Mabjeesh et al., 1998).

A concentração de $\mathrm{N}$-ureico mais elevada nas ovelhas que receberam dietas de flushing após a ovulação em relação àquelas que receberam a dieta de mantença indica que, independentemente da degradabilidade da proteína, o consumo de PB acima das exigências nutricionais aumenta a concentração de $\mathrm{N}$-ureico no plasma (Elrod e Butler, 1993; Butler, 2005). Contudo, a origem da amônia, que contribuiu para o aumento do $\mathrm{N}$-ureico, foi diferente, de acordo com a dieta consumida. As ovelhas que consumiram o FFS após a ovulação tiveram o excesso de amônia chegando à corrente sanguínea através da parede ruminal, enquanto aquelas que consumiram a dieta de FGM+FA podem ter apresentado maior deaminação, no fígado, dos aminoácidos absorvidos no intestino. Após a absorção no intestino, os aminoácidos são utilizados pelos tecidos do animal, principalmente para a síntese de proteínas. Os aminoácidos não utilizados na síntese de proteínas são deaminados, originando amônia e esqueletos carbônicos (Santos e Greco, 2007). A concentração de N-ureico das ovelhas do tratamento T3 foi similar à observada por Mabjeesh et al. (1998) em amostras de sangue coletadas de vacas leiteiras às três e às seis horas após o fornecimento de dieta formulada com caroço de algodão e glúten de milho (23,0 e $19,0 \mathrm{mg} / \mathrm{dL}$, respectivamente).
As ovelhas que consumiram dietas de flushing antes e depois da ovulação e as que receberam dietas de flushing antes da ovulação e dieta de mantença após a ovulação não apresentaram diferença $(\mathrm{P}>0,05)$ na taxa de gestação (Tab. 5).

Tabela 5. Taxa de gestação (\%) das ovelhas experimentais, submetidas a diferentes dietas

\begin{tabular}{cc}
\hline Tratamento & Taxa de gestação $(\%)$ \\
\hline T1 & $75(9 / 12)$ \\
T2 & $91(10 / 11)$ \\
T3 & $80(8 / 10)$ \\
T4 & $70(7 / 10)$ \\
\hline
\end{tabular}

De acordo com Parr et al. (1993) e O`Callaghan e Boland (1999), a manutenção do alto nível nutricional após a cobertura pode levar à maior metabolização de progesterona pelo fígado, reduzindo sua concentração sanguínea e resultando em menor taxa de gestação. McKelvey et al. (1988), citados por Gordon (1997), relataram que alto plano nutricional após a monta pode adversamente influenciar a sobrevivência embrionária e que este processo é mediado por declínio da concentração plasmática de progesterona. Segundo os autores, o baixo plano nutricional neste período não influenciou a sobrevivência dos embriões.

Embora a concentração de progesterona neste estudo não tenha sido analisada, os resultados sugerem que a manutenção de alto nível nutricional após a cobertura não aumentou a metabolização deste hormônio em magnitude suficiente para reduzir a taxa de gestação. Além da possível vantagem em relação à manutenção da concentração sanguínea de progesterona adequada ao desenvolvimento do embrião, o fornecimento de uma dieta de mantença ainda apresenta vantagens econômicas. 
Branca et al. (2000) também não observaram diferença na taxa de concepção de ovelhas suplementadas com dietas isoproteicas contendo glúten de milho ou farelo de soja, diferindo na quantidade de PNDR (46 ou 86g/dia). Como as ovelhas consumiram volumoso rico em PDR, os autores sugeriram que a substituição de PDR por PNDR não aumenta a taxa de concepção em ovelhas que são alimentadas com dietas ricas em PDR. Da mesma forma, neste estudo, as ovelhas consumiram um volumoso rico em NNP e PDR. Sendo assim, o possível efeito benéfico de PNDR sobre a taxa de gestação pode ter sido mascarado pelo NNP e PDR presentes na silagem de milho.

Ao contrário do observado neste estudo, Elrod e Butler (1993) observaram menor taxa de gestação em novilhas que receberam dieta que excedeu em $50 \%$ a exigência de PDR do que nas que receberam a dieta que atendeu à exigência de PDR (61\% e $82 \%$, respectivamente). Além disso, vários autores observaram relação inversa entre concentração de $\mathrm{N}$-ureico no sangue e taxa de concepção de vacas (Canfield et al., 1990; Ferguson et al., 1993; Butler et al., 1996; Rhoads et al., 2006), principalmente em concentrações superiores a $19 \mathrm{mg} / \mathrm{dL}$. Em ovelhas, Branca et al. (2000) relataram tendência de maior taxa de concepção associada à concentração de $\mathrm{N}$-ureico no leite inferior a $26,13 \mathrm{mg} / \mathrm{dL}$, em comparação a valores superiores a este $(64 \%$ vs. $44 \%$, respectivamente), e McEvoy et al. (1997) verificaram que as taxas de gestação foram de $75 \%, 71 \%$ e $33 \%$, em ovelhas com concentração de N-ureico no plasma de 5,59, 14,25 e $19,84 \mathrm{mg} / \mathrm{dL}$, respectivamente.

O excesso de PB na dieta pode alterar o ambiente uterino ao ocasionar alterações na concentração iônica (Jordan et al., 1983; Rhoads et al., 2004), redução no pH (Elrod et al., 1993; Elrod e Butler, 1993) e aumento na concentração de amônia no fluido uterino (Hammon et al., 2005). Estes fatores podem alterar o desenvolvimento embrionário nos 11 primeiros dias, retardando a sua proliferação celular e diminuindo o número de embriões viáveis (McEvoy et al., 1997). Estes autores observaram que $80 \%, 70 \%$ e $40 \%$ das ovelhas não suplementadas, suplementadas com 15 ou $30 \mathrm{~g}$ de ureia/dia, apresentaram embriões viáveis, respectivamente.
Neste estudo, não foi observado efeito $(\mathrm{P}>0,05)$ da degradabilidade ruminal da proteína e do nível nutricional após a ovulação sobre a prolificidade (Tab. 6).

Tabela 6. Média e erro-padrão da prolificidade das ovelhas, submetidas a diferentes dietas

\begin{tabular}{cc}
\hline Tratamento & Prolificidade $^{1}$ \\
T1 & $1,90 \pm 0,27$ \\
T2 & $2,20 \pm 0,26$ \\
T3 & $2,13 \pm 0,29$ \\
T4 & $1,71 \pm 0,32$ \\
\hline
\end{tabular}

${ }^{1}$ Número de cordeiros nascidos/ovelhas prenhes.

Molle et al. (1995) não observaram diferença na prolificidade de ovelhas suplementadas com $270 \mathrm{~g}$ de farelo de soja ou $250 \mathrm{~g}$ de milho, diariamente, durante duas semanas antes até três semanas após a introdução do macho no rebanho, comparadas às não suplementadas $(1,3 ; 1,1$ e 1,1 cordeiro/ovelha, respectivamente). No entanto, Molle et al. (1997) observaram que ovelhas da raça Sarda, suplementadas com $270 \mathrm{~g}$ de farelo de soja/dia a partir de 14 dias antes e até dois dias após a monta, apresentaram maior prolificidade (1,7 cordeiro) do que as ovelhas suplementadas a partir de 14 dias antes até 21 dias após a introdução do carneiro (1,5 cordeiro) e do que aquelas não suplementadas (1,3 cordeiro). Os autores relatam que o aumento do nível nutricional durante o primeiro mês de gestação está associado à perda embrionária. Contudo, no presente estudo, a manutenção de alto nível nutricional durante os 28 dias após a ovulação não foi prejudicial à taxa de gestação e à prolificidade.

\section{CONCLUSÕES}

O fornecimento de alimentos proteicos com diferentes proporções de PDR, nos níveis utilizados neste estudo, não influenciou a concentração plasmática de $\mathrm{N}$-ureico, a taxa de gestação e a prolificidade. O nível nutricional (flushing vs. mantença) após a ovulação não alterou a taxa de gestação e a prolificidade.

\section{AGRADECIMENTOS}

À UFLA, pela oportunidade de condução deste estudo; à FAPEMIG, pelo financiamento do projeto; ao $\mathrm{CNPq}$, pela concessão da bolsa de estudos; à empresa Tecnopec, pela doação dos hormônios; aos colegas que ajudaram na condução do experimento. 


\section{REFERÊNCIAS}

ABECIA, J.A.; LOZANO, J.M.; FORCADA, F. et al. Effect of level of dietary energy and protein on embryo survival and progesterone production on day eight of pregnancy in Rasa Aragonesa ewes. Anim. Reprod. Sci., v.48, p.209-218, 1997.

AGRICULTURAL and Food Research Council. Energy and protein requirements of ruminants. Wallingford: CAB International, 1993. 159p.

BRANCA, A.; MOLLE, G.; SITZIA, M. et al. Short-term dietary effects on reproductive wastage after induced ovulation and artificial insemination in primiparous lactating Sarda ewes. Anim. Reprod. Sci., v.58, p.59-71, 2000.

BUTLER, W.R. Relationships of dietary protein and fertility. Adv. Dairy. Tech., v.17, p.159-161, 2005.

BUTLER, W.R.; CALAMAN, J.J.; BEAM, S.W. Plasma and milk urea nitrogen in relation to pregnancy rate in lactating dairy cattle. J. Anim. Sci., v.74, p.858-865, 1996.

CANFIELD, R.W.; SNIFFEN, C.J.; BUTLER, W.R. Effects of excess degradable protein on postpartum reproduction and energy balance in dairy cattle. J. Dairy Sci., v.73, p.2342-2349, 1990.

CORNELL Net Carbohydrate and Protein System: version 5.0. Cornell University, 2003. Software.

COSTA, R.M. Avaliação de suplementos com proteína degradável e de escape ruminal para recria de bovinos. 2001. 24f. Dissertação (Mestrado em Zootecnia) - Universidade Estadual Paulista, Jaboticabal.

ELROD, C.C.; BUTLER, W.R. Reduction of fertility and alteration of uterine $\mathrm{pH}$ in heifers fed excess ruminally degradable protein. J. Anim. Sci., v.71, p.694-701, 1993.

ELROD, C.C.; VAN AMBURGH, M.; BUTLER, W.R. Alterations of $\mathrm{pH}$ in response to increased dietary protein in cattle are unique to the uterus. J. Anim. Sci., v.71, p.702-706, 1993.

FERGUSON, J.D.; GALLIGAN, D.T.; BLANCHARD, T. et al. Serum urea nitrogen and conception rate: the usefulness of test information. J. Dairy Sci., v.76, p.3742-3746, 1993.
GORDON, I. Controlled reproduction in sheep \& goats. New York: CAB International, 1997. 450p.

HAMMON, D.S.; HOLYOAK, G.R.; DHIMAN, T.R. Association between blood plasma urea nitrogen levels and reproductive fluid urea nitrogen and ammonia concentrations in early lactation dairy cows. Anim. Reprod. Sci., v.86, p.195-204, 2005.

JORDAN, E.R.; CHAPMAN, T.E.; HOLTAN, D.W. et al. Relationship of dietary crude protein to composition of uterine secretions and blood in high-producing postpartum dairy cows. J. Dairy Sci., v.66, p.1854-1862, 1983.

LANDAU, S.; HOUGHTON, J.A.; MAWHINNEY, J.R. et al. Protein sources affect follicular dynamics in ewes near the onset of breeding season. Reprod. Fertil. Develop., v.8, p.1021-1028, 1996.

MABJEESH, S.J.; ARIELI, A.; ZAMWELL, S. et al. Heat-treated whole cottonseed versus maize gluten meal as a rumen undegradable protein supplement for lactating dairy cows. Livest. Prod. Sci., v.55, p.249-259, 1998.

McEVOY, T.G.; ROBINSON, J.J.; AITKEN, R.P. et al. Dietary excesses of urea influence the viability and metabolism of preimplantation sheep embryos and may affect fetal growth among survivors. Anim. Reprod. Sci., v.47, p.7190, 1997.

McKELVEY, W.A.C.; ROBINSON, J.J; AITEKEN, R.P. The use of reciprocal embryo transfer to separated the effects of pre-and-postmating nutrition on embryo survival and growth to the ovine conceptus. In: International Congress Animal Reproduction and AI, 11., 1988, Dublin, Anais... Dublin: [s.n.] 1988. p.176.

MOLLE, G.; BRANCA, A.; LIGIOS, S. et al. Effect of grazing background and flushing supplementation on reproductive performance in Sarda ewes. Small Rum. Res., v.17, p.245-254, 1995.

MOLLE, G.; LANDAU, S.; BRANCA, A. et al. Flushing with soybean meal can improve reproductive performances in lactating Sarda ewes on a mature pasture. Small Rum. Res., v.24, p.157-165, 1997. 
O'CALLAGHAN, D.; BOLAND, M.P. Nutritional effects on ovulation, embryo development and the establishment of pregnancy in ruminants. Anim. Sci., v.69, p.299-314, 1999.

OCAK, N.; CAM, M.A.; KURAN, M. The influence of pre- and post-mating protein supplementation on reproductive performance in ewes maintained on rangeland. Small Rum. Res., v.64, p.16-21, 2006.

OLIVEIRA, M.A.L.; REICHENBACH, H.D.; SANTOS, M.H.B.; TENÓRIO FILHO, F. Aplicabilidade do scan $B$ na reprodução de pequenos ruminantes. In: SANTOS, M.H.B.; OLIVEIRA, M.A.L.; LIMA, P.F. Diagnóstico de gestação na cabra e na ovelha. São Paulo: Varela, 2004. p.85-96.

PARR, R.; DAVIS, I.F.; FAIRCLOUGH, R. et al. Overfeeding during early pregnancy reduces peripheral progesterone concentration and pregnancy rate in sheep. J. Reprod. Fertil., v.80, p.317-320, 1987.

PARR, R.; DAVIS, I.F.; MILES, M.A. et al. Liver blood flow and metabolic clearence rate of progesterone in sheep. Res. Vet. Sci., v.55, p.311316, 1993.

RHIND, S.M.; McKELVEY, W.A.C.; McMILLEN, S.R. et al. Effect of restricted food intake before and/or after mating, on the reproductive performance of Greyface ewes. Anim. Prod., v.48, p.149-155, 1989.
RHOADS, M.L.; GILBERT, R.O.; LUCY, M.C. et al. Effects of urea Infusion on the uterine luminal unvironment of dairy cows. J. Dairy Sci., v.87, p.2896-2901, 2004.

RHOADS, M.L.; RHOADS, R.P.; GILBERT, R.O. et al. Detrimental effects of high plasma urea nitrogen levels on viability of embryos from lactating dairy cows. Anim. Reprod. Sci., v.91, p.1-10, 2006.

SANTOS, F.A.P.; GRECO, L.F. Digestão pós-ruminal de proteínas e exigências de aminoácidos para ruminantes. In: SIMPÓSIO INTERNACIONAL AVANÇOS EM TÉCNICAS DE PESQUISA EM NUTRIÇẪO DE RUMINANTES, 2007, Pirassununga. Anais... Pirassununga: Universidade de São Paulo, 2007. p.122-159.

SILVA, D.J.; QUEIROZ, A.C. Análise de alimentos: métodos químicos e biológicos. 3.ed. Viçosa: UFV, 2002. 235p.

STATISTICAL analyses system institute. SAS/STAT user's guide: statistics. 4nd ed. Cary, 1997. v.2, 943p.

SMALL Ruminant Nutrition System: version 1.8.4. College Station, 2008. Texas University. Software. 